Rakenteiden Mekaniikka (Journal of Structural Mechanics)

Vol. 50, No 3, 2017, pp. $353-356$

https://rakenteidenmekaniikka.journal.fi/index

https://doi.org/10.23998/rm.64925

(c) The author(s) 2017.

Open access under CC BY-SA 4.0 license.

\title{
Concept calculation tool for dynamics of generator set common baseframe
}

\author{
Johannes Heilala $^{1}$, Teemu Kuivaniemi, Juho Könnö and Tero Frondelius
}

Summary. The natural frequency and vibration response calculation process of a generator set was automatized so that it can be used in a generator set common base frame concept design. The implementation of automatization was to be done so that no profound knowledge about the finite element method is needed to execute calculations and that computation times are short. Substructuring is used for certain parts of the generator set model to reduce the computation times for more a efficient concept design process. The common base frame concept design is implemented to the process by using a design tool in which the finite element model generation from parametric geometry is automatized. Generator set finite element model generation, natural frequency and vibration response calculations and post-processing of analysis results were implemented by developing a calculation tool for this purpose. The calculation tool is an independent application that uses Abaqus simulation software to execute analyses.

Key words: generator set, natural frequencies, vibration response, substructures, Wärtsilä

Received 15 June 2017. Accepted 19 August 2017. Published online 21 August 2017.

\section{Introduction}

One of the main aspects in the common base frame design process is to adjust the mechanical properties of a common base frame so that excitations caused by engine running conditions [6] are not in resonance with the natural frequencies of a generator set. Vibration levels of a generator set can rise significantly if resonance occurs, and high vibration levels can lead to failures in structures.

The main interest in common base frame concept design is in the eigenmodes that have large displacements in the whole generator set, for example bending and torsion of the common base frame [6]. Also eigenmodes of the turbocharger and its mounting bracket are considered important [4]. These can be adjusted by the design of the common base frame so that the vibration levels of the generator set in engine running conditions will not get too high, i.e. the excitation forces in the engine are not in resonance with the natural frequencies of the generator set.

Finite element analyses are required to calculate the response levels and mass and inertia properties of a generator set. An easy approach to these analyses is required to implement them to the concept design of a common base frame. The execution of these

\footnotetext{
${ }^{1}$ Corresponding author. johannes.heilala@gbw.fi
} 
analyses should be so trivial that any common base frame designer can do it independently, without a wide knowledge of analysis techniques, and use the results obtained from analyses to modify the design if needed.

This requires automatization of the generator set finite element model generation, execution of analyses, and post-processing of results, which is this paper novelty. The work presented here is the proof-of-concept for the Wärtsilä Digital Design Platform [5], which from now on store these automated simulation processes and models.

\section{Finite element analysis}

To study the dynamic properties of a generator set, a natural frequency and vibration response analysis needs to be executed. The natural frequencies and eigenmodes of a generator set are calculated with a natural frequency extraction step. Also the mass and inertia properties of the model are calculated in this step. The natural frequency extraction step is a linear analysis that solves the undamped eigenvalue problem for symmetric mass and stiffness matrices [1]. The natural frequency analysis results are later used in a response analysis.

The response analysis is a mode-based steady-state dynamic analysis. The influence of excitation forces which simulate the loads acting in the operating conditions of an engine are added to the model in this analysis. The steady-state linear dynamic analysis predicts the responses in a structure caused by continuous harmonic excitation [1].

\section{Substructures}

The Craig-Bampton substructuring method is used to create substructures for generator set models. This method can be used to re-characterize the finite element models into a set of relatively small matrices. These matrices contain mass and stiffness properties and mode shape information of the fundamental low-frequency response modes of the model and can be used to perform a wide range of dynamic analyses [3]. In the Craig-Bampton method the mode shapes used to define degrees of freedom of a substructure are fixed [9].

The substructures are generated without recovery matrices to reduce the size of the substructure files. This prevents them from being visualized. To study the eigenmodes of a generator set, a shell element mesh is created to the retained nodes of substructures to see the basic shapes of the substructure components. These shell elements are defined in a way that they do not affect the mass and stiffness of the model.

\section{Common base frame design tool}

A parametric design tool developed for Siemens NX software is used to create a finite element model from the concept design of a common base frame. In the design tool, the geometry of the common base frame is parametrized and the finite element model generation automatized. This allows the designer to easily change the design of a common base frame model used in analyses.

\section{Calculation tool for generator set dynamics}

The automatization of calculating natural frequencies, mass and inertia properties and vibration response levels of a generator set as a part of the common base frame concept design process is done by developing an independent application for this purpose. The 
application is designed so that a user can run analyses without a profound understanding of the finite element method. The calculation tool is an independent application software built to run in a calculation cluster with Linux environment. The main routine of the application has been written using the Python object-oriented programming language. A graphic user interface has been created for the calculation tool to make it more userfriendly.

The user can define different components for an engine and a generator by engine type and cylinder configuration. Also the stiffness of the mounting springs of the generator set, mass and inertia properties of the flyweel and coupling, rotating and oscillating masses in the engine and the distance between the engine and the generator can be defined in the application.

Only the common base frame model is a conventional finite element model in the full generator set model. The application uses substructures for the rest of the main components to generate a complete generator set model from a user-defined configuration. These substructures can be easily generated from virtual engine models used in multi body dynamic simulations $[2,7,8]$ and added to the database the application uses. This database also contains response analysis Abaqus input files for different engine types. Spring, point mass and rotary inertia elements are used to add the user defined mounting springs and mass and inertia properties to the generator set model.

Running the analyses, post-processing the analysis results and report generation is automatized in the application. The information about the user-defined generator set configuration, mass and inertia properties and natural frequencies of the generator set are written to a results text file. Visual reports are created from eigenmode animations and vibration levels in the generator set measurement points. An example of a vibration level report is presented in Figure 1.

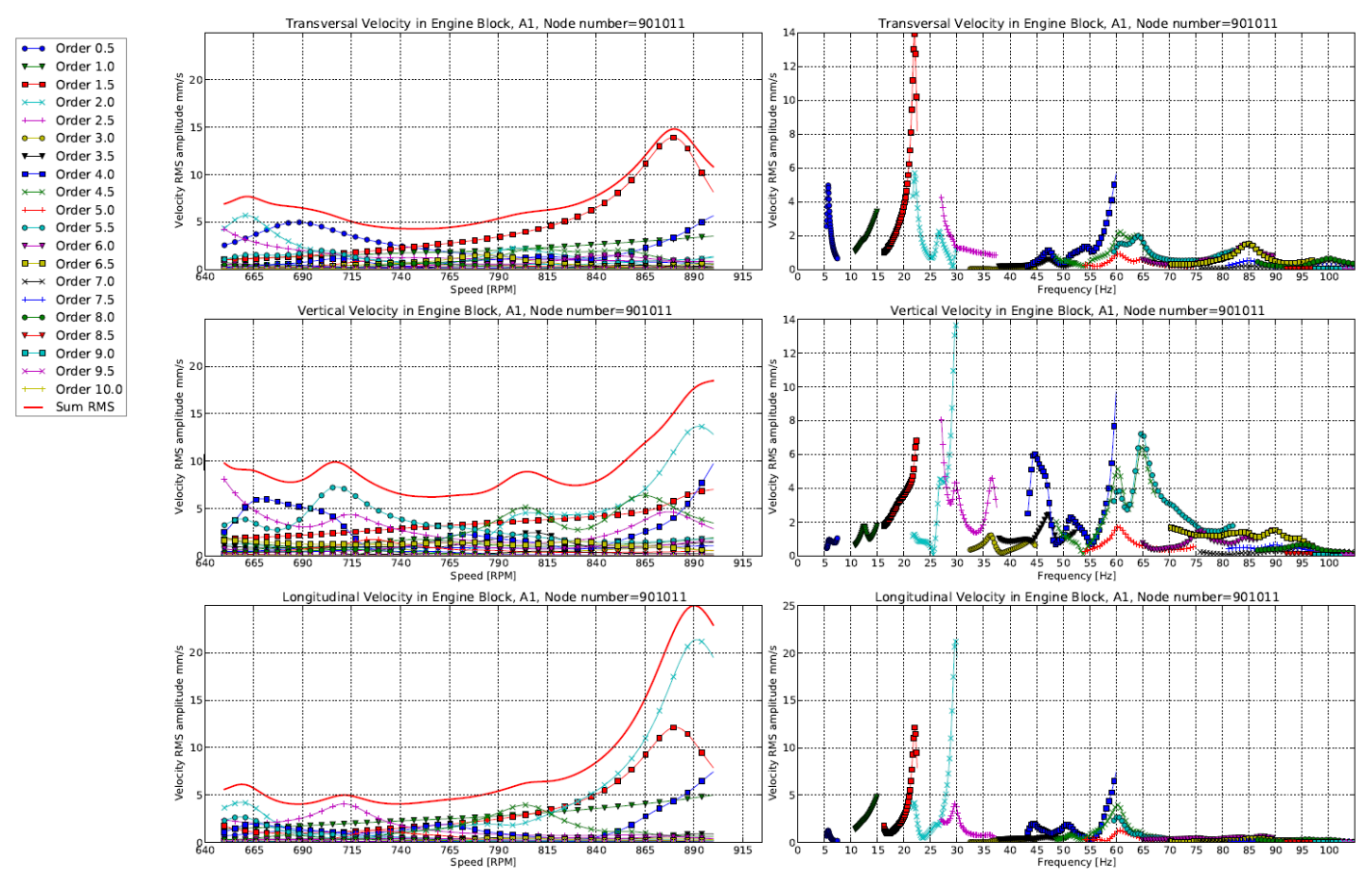

Figure 1. Vibration levels in a single generator set measurement point 


\section{Conclusions}

This paper presents the proof-of-concept for Wärtsilä Digital Design Platform [5]. Simulation driven design process demands simulations to be performed upfront in the process, thus tool that does not require expertize, but can be used by any designer, was developed.

The iterative process of the concept design of a common base frame can be done easily with the common base frame design tool and the calculation tool for generator set dynamics. The designer can easily modify the common base frame design based on the analysis results and re-calculate the dynamic properties of the generator set with a new design. Because of the use of substructures, the computation times of analyses are short. This reduces the time used to study the properties of a single design of a common base frame.

\section{References}

[1] Abaqus 6.14 Documentation: Abaqus Analysis User's Guide. Dassault Systémes Simulia Corp, Providence, RI, USA, 2014.

[2] Jussi Göös, Anton Leppänen, Antti Mäntylä, and Tero Frondelius. Large bore connecting rod simulations. Rakenteiden Mekaniikka, 50(3):275-278, 2017. URL https://doi .org/10. $23998 / \mathrm{rm} .64658$.

[3] William Haile. Primer on the craig-bampton method. John T. Young, editor, 2000.

[4] Evgeniya Kiseleva, Juho Könnö, Niclas Liljenfeldt, Teemu Kuivaniemi, and Tero Frondelius. Topology optimisation of the in-line engine turbocharger bracket. Rakenteiden Mekaniikka, 50(3):323-325, 2017. URL https://doi.org/10.23998/rm.65071.

[5] Juho Könnö, Hannu Tienhaara, and Tero Frondelius. Wärtsilä digital design platform. Rakenteiden Mekaniikka, 50(3):234-238, 2017. URL https://doi.org/10.23998/rm.64621.

[6] Antti Korpela, Marko Jokinen, Teemu Kuivaniemi, and Tero Frondelius. W4L20 VEBIC genset dynamics — baseframe design. Rakenteiden Mekaniikka, 50(3):292-295, 2017. URL https://doi.org/10.23998/rm.64943.

[7] Teemu Kuivaniemi, Antti Mäntylä, Ilkka Väisänen, Antti Korpela, and Tero Frondelius. Dynamic gear wheel simulations using multi body dynamics. Rakenteiden Mekaniikka, 50 (3):287-291, 2017. URL https://doi.org/10.23998/rm.64944.

[8] Antti Mäntylä, Jussi Göös, Anton Leppänen, and Tero Frondelius. Large bore engine connecting rod fretting analysis. Rakenteiden Mekaniikka, 50(3):239-243, 2017. URL https://doi.org/10.23998/rm.64914.

[9] Zu-Qing Qu. Model order reduction techniques with applications in finite element analysis. Springer Science \& Business Media, 2013.

Johannes Heilala

Global Boiler Works Oy

Lumijoentie 8,90400 Oulu

johannes.heilala@gbw.fi

Teemu Kuivaniemi, Juho Könnö and Tero Frondelius

Wärtsilä

Järvikatu 2-4, 65100 Vaasa

teemu.kuivaniemi@wartsila.com, juho.konno@wartsila.com, tero.frondelius@wartsila.com 